\title{
Numerical and experimental investigations to analyze the micro-hole drilling process in spark-assisted chemical engraving (SACE)
}

\author{
Viveksheel Rajput ${ }^{1} \cdot$ Mudimallana Goud $^{1} \cdot$ Narendra Mohan Suri $^{1}$
}

Received: 20 March 2020 / Accepted: 6 August 2020 / Published online: 18 August 2020

(c) Springer Nature Switzerland AG 2020

\begin{abstract}
With the increased utilization of glass in micro-electromechanical systems (MEMS) applications, need is generated to produce micro-features on glass with excellent surface quality, i.e., better hole circularity and less thermal cracks. Sparkassisted chemical engraving (SACE) has proven to be an emerging and reliable technology for micro-machining of glass that includes local joule heating of the work material for its removal. However, some problems need to be covered in the micro-hole drilling process such as low machining depth, low aspect ratio, high thermal cracks, and an increase in machining time with the increase in depth. Moreover, few finite element modeling (FEM) studies have been reported to analyze the material removal aspects in SACE. This present study developed the FEM-based thermal model to analyze the material removal rate (MRR) and investigated the different machining conditions to improve the micro-hole drilling process in SACE. Improvement in depth and aspect ratio can be achieved by using a different tool's shape which variably enhances the flow of electrolytes and thereby increases the formation rate of gas film. Pointed and cylindrical tools were used for micro-drilling operations. MRR, hole entrance diameter, machining depth, aspect ratio, thermal cracks, and machining time were observed under different machining conditions. FEM study revealed that MRR improves with the increase in both the applied voltage and electrolyte concentration. The MRR was predicted by utilizing the plots of temperature distributions and was found in accordance with the experimental results of MRR. The experimental study concluded that the pointed tool produced micro-holes with a higher machining depth and aspect ratio at an improved machining rate, while the cylindrical tool produced micro-holes with a smaller number of thermal cracks and better circularity.
\end{abstract}

Keywords Material removal rate $\cdot$ Gravity feed $\cdot$ Micro-holes $\cdot$ SACE $\cdot$ Aspect ratio $\cdot$ Cracks

\section{Introduction}

The utilization of glass materials in the field of MEMS such as micro-sensors, micro-needles, and micro-pumps has been escalating at a very rapid rate. It has initiated the product miniaturization that further necessitates the development of more reliable and effective micro-machining processes. Glass has several desirable properties like high chemical resistance, low electrical conductivity, and transparency that are vital for MEMS applications [1, 2]. SACE is one of the hybrids and novel processes used for micro-machining of non-conductive materials such as glass, quartz, and ceramics, which combines the machining attributes or material removal mechanism of both the electro-discharge machining (EDM) and electrochemical machining (ECM) simultaneously. It consists of tool electrode as a cathode, auxiliary electrode as an anode, and work material which are all dipped inside the aqueous solution of an electrolyte as shown in Fig. 1.

A DC power supply is applied across the cathode and anode which are separated by a distance of few centimeters (known as the inter-electrode gap, IEG). It prompts

$\triangle$ Viveksheel Rajput, Sheelrajput03@gmail.com | Department of Production and Industrial Engineering, PEC, Chandigarh, India. 
Fig. 1 SACE setup [3]

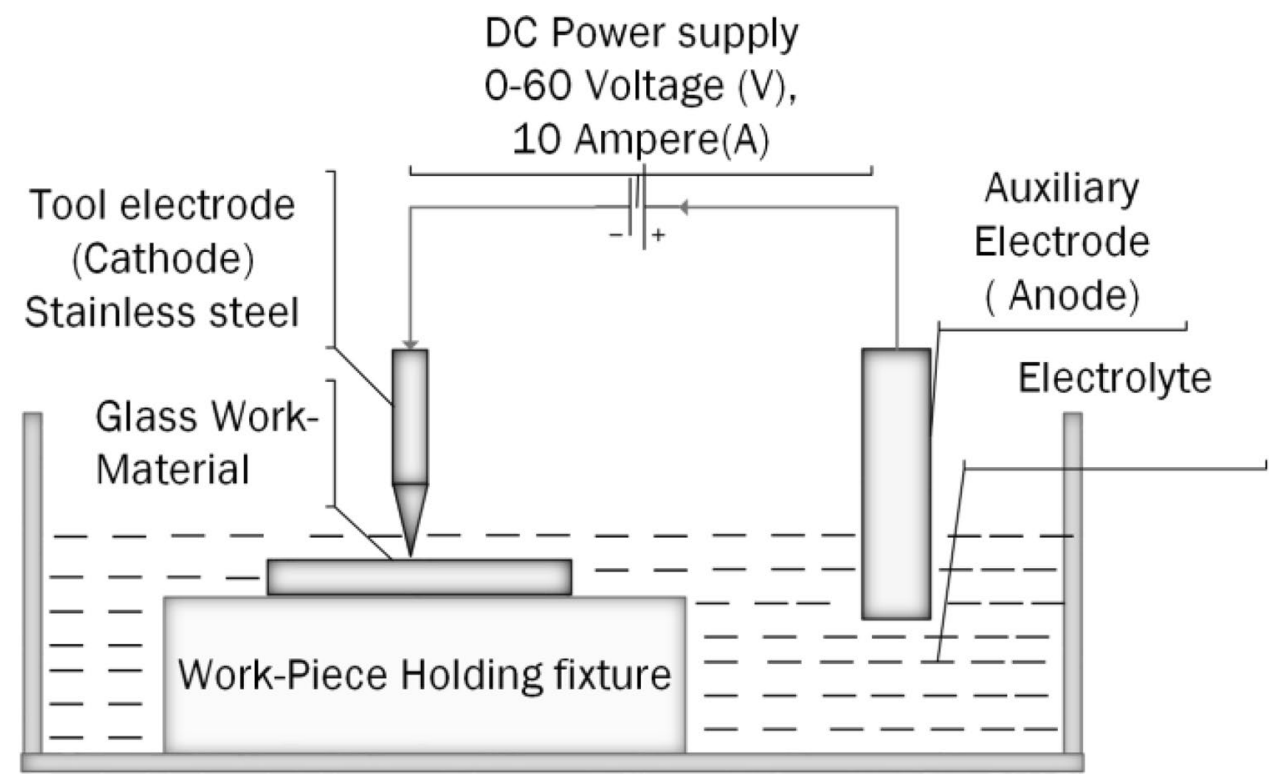

the generation of tiny hydrogen gas bubbles and oxygen gas bubbles at the cathode and anode, respectively. With the further increase in voltage, the rate of formation of hydrogen bubbles increases that raises their density at the tool surrounding area. It leads to the bubbles' coalescence with each other physically to form a gas film at the tool surrounding area which constricts the current flow. This results in the spark generation due to the electric breakdown of the gas film. The work material is then placed and maintained underneath the tool tip at a very small distance, and material removal takes place due to thermal melting (EDM) and chemical etching action (ECM).

SACE was first demonstrated by Kurafuji and Suda [4] in 1968 during glass drilling using the electric sparks and described the possibility of machining non-conductive materials. It is also known by several other names like electrochemical arc machining [5], electrochemical discharge machining [6], and electrochemical spark machining [7]. The concept of spark generation in SACE was briefly described by Basak and Ghosh $[8,9]$ in which they proposed critical current-voltage parameters and stated that spark mechanism is similar to a switching on/off action of an electric switch. El-Haddad et al. [10] developed a model for predicting current and voltage values required for stable gas film formation by adopting the principle of gas film dynamics.

Wuthrich et al. $[10,11]$ successfully drilled micro-holes in non-conductive materials and observed that gas film stability plays a vital role in determining the efficiency of spark. Lim et al. [12] fabricated micro-holes using constant tool feed and observed a taper phenomenon due to prolonged exposure of undesirable sparks at the hole entrance. Wuthrich et al. [13] demonstrated the application of gravity-assisted tool feed and mentioned that electrolyte flow was difficult to achieve at higher machining depth. The drilling process was divided into two regimes: (i) discharge regime (depth $<300 \mu \mathrm{m}$ ) where discharges control the machining and (ii) hydrodynamic regime (depth > $300 \mu \mathrm{m}$ ) [14] where material removal significantly depends upon electrolyte availability. Thus, machining speed was less in the case of the hydrodynamic regime due to lack of electrolyte which further can be improved by enhancing electrolyte flow. Moreover, the tool electrode shape substantially affects the machining efficiency and machining depth in micro-drilling operations due to different discharge energy concentrations at the tool electrode surface thereby giving variable machining quality. Zheng et al. [15] utilized a flat sidewall tool to reduce the taper phenomenon that occurred due to discharge from the sides of the tool. Wuthrich et al. [16] stated that a needle-shaped tool helps in concentrating the discharge at the tool electrode tip. Rajput et al. [17] investigated the effect of different shapes of the tool electrode on MRR and optimized the input parameters for maximum MRR. It was found that tool shape significantly affects the machining performance. Yang et al. [18] evaluated the improvement in machining performance and shape quality by using a spherical tool electrode in comparison with the cylindrical tool electrode. SACE performance also depends upon the selection of discrete input parameters such as applied voltage, electrolyte concentration, inter-electrode gap, and tool feed. Sundaram et al. [19] studied the effect of pulse voltage on gas film formation and machining quality. They found that pulse electrochemical discharge machining (PECDM) results in smaller hole diameter and reduced heat-affected zone. Many reporters emphasized 
that material removal in the SACE process increases with the increase in applied voltage due to an increase in the bubble formation process and spark intensities. However, high voltage tends to produce an enlarged hole diameter with more thermal cracks [20-22]. Singh et al. [23] stated that the tool feed rate is one of the important parameters determining the machining quality of micro-hole drilled on a silicon wafer. They concluded that low tool feed $(100 \mu \mathrm{m} / \mathrm{min}$ ) leads to smooth cut owing to prolong contact of spark energy, while it was observed high tool feed $(250 \mu \mathrm{m} / \mathrm{min})$ results into minimum overcut. Numerous studies were reported in the performance evaluation of different input parameters in the SACE process [24-28]. Rajput et al. [29] studied the effect of different process parameters in SACE and highlighted the future areas also. An illustration of different input process parameters as the fishbone diagram is shown in Fig. 2. A summarized report on the utilization of different shapes of tool electrode and their effect on machining characteristics are shown in Fig. 3.

Apart from experimental studies, numerous analytical studies have been reported for analyzing the performance of SACE. Finite element-based modeling has been proven to be a successful method for analyzing the different processes by disintegrating the problems into simpler and smaller elements [30-35]. Bhondwe et al. [34] established a FEM-based 2D thermal model for predicting the MRR by observing the temperature fields within the work material. The experiments were performed to assess the model validations. A good agreement was seen with the FEM predicted results. Wei et al. [35] estimated the amount of energy transference into the work material by developing the axisymmetric $2 \mathrm{D}$ thermal model for drilling in the discharge regime. Goud et al. [36] developed a 3D FEM model for predicting the removal rate of soda-lime glass and alumina material due to a single spark. The MRR was estimated for a single spark by recording the temperature values at the nodes and further post-processed for the total number of sparks per unit. Experimental results demonstrated a fair agreement with the simulation results. The MRR of soda-lime glass was found higher than the alumina material. Panda and Yadava [37] evaluated the MRR in wire-assisted SACE process with FEM-based thermal model. The model predictions were found higher than the experimental results that were explained due to the assumptions of $100 \%$ ejection efficiency.

From the literature, it is evident that many investigations have been done on glass using SACE for producing micro-holes with gravity tool feed but low machining depths, low aspect ratios, and high thermal cracks are still a challenging task to figure out. The lack of electrolyte availability at the higher depths results in a decrease in the drilling speed and consumes more machining time. Additionally, it also results in low machining depths and aspect ratio. The deep drilling in the SACE process is seen in terms of machining depth and aspect ratio. Further, the desire to obtain higher depths with increased voltage and concentration produces more thermal cracks at the hole edge due to prolonged exposure of the work material surface to the sparks. The use of different tool shapes can produce variable results during drilling with gravity feed as it controls the electrolyte flow and sparks concentration.

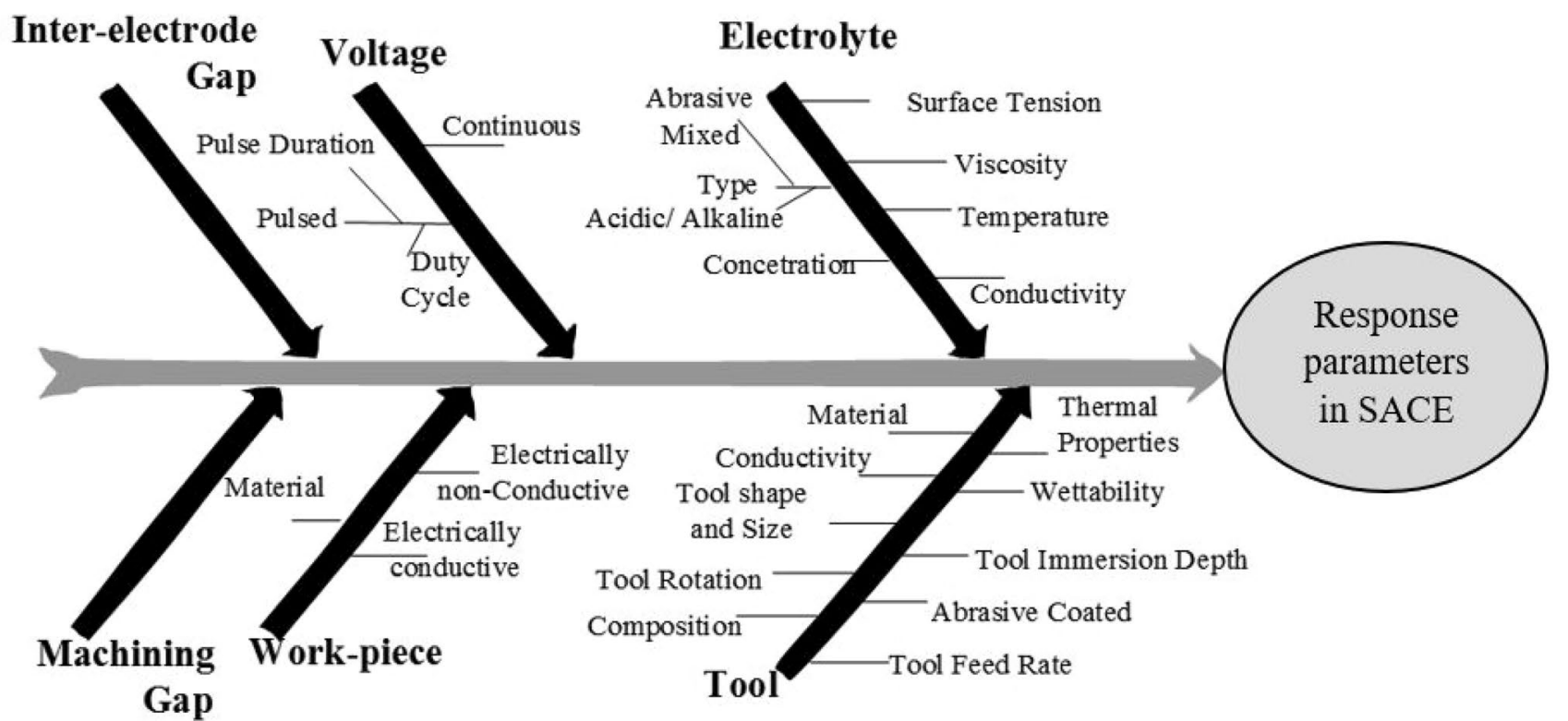

Fig. 2 Fishbone diagram of different input parameters 


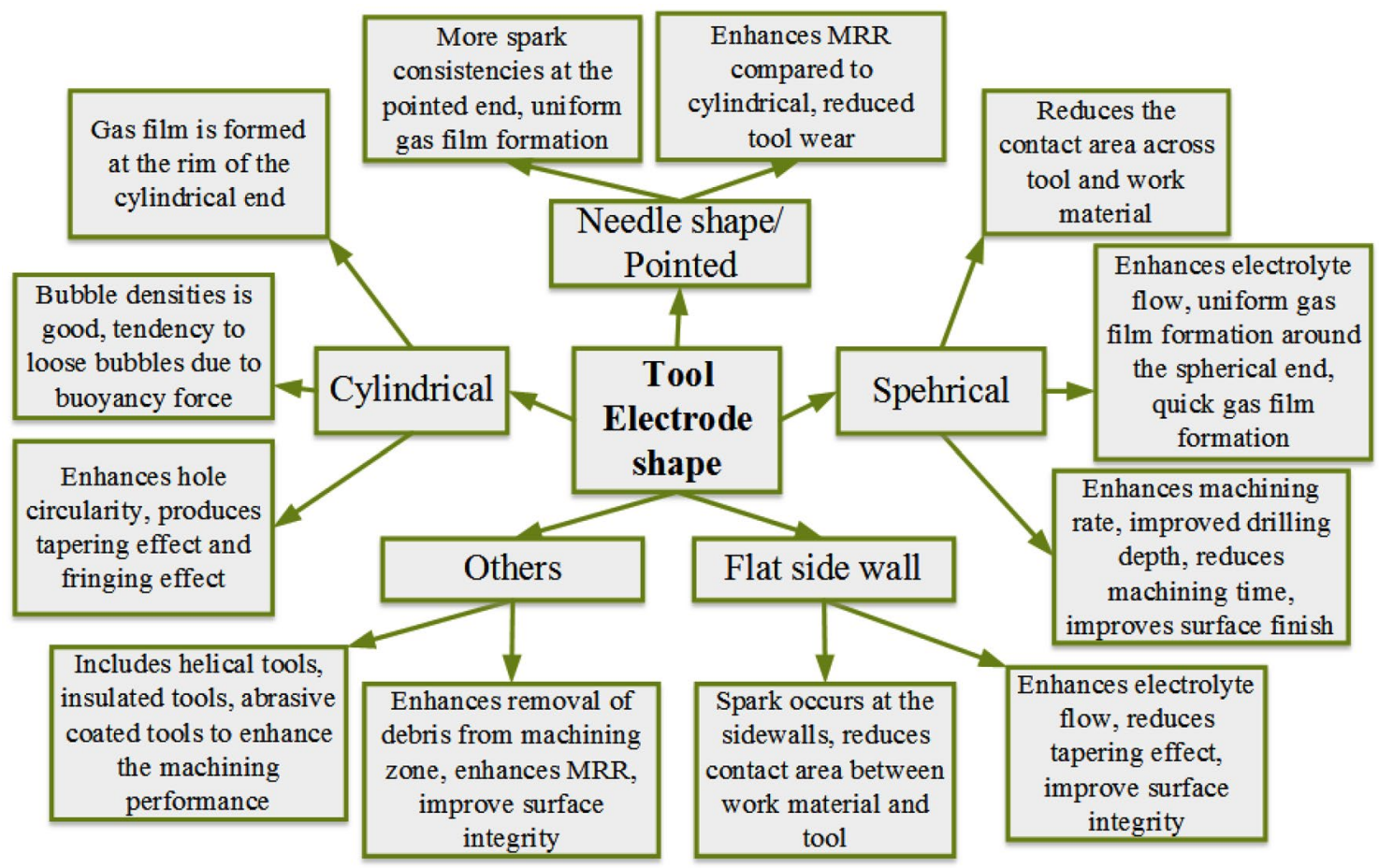

Fig. 3 Summarized report on the utilization of different tool shapes in SACE process

Moreover, FEM-based thermal modeling can also be effectively utilized to assess the material removal analysis of the SACE process. Therefore, more numerical and experimental investigations are required for studying and improving the MRR.

This paper discussed the development of the FEMbased thermal model to investigate the MRR and its validation through experimental studies. The effect of utilizing the different tool shapes on SACE machining performance in terms of MRR, hole entrance diameter, machining depth, aspect ratio, thermal cracks, and machining time was investigated during the fabrication of micro-holes on the glass. The consideration of these responses simultaneously for gravity feed SACE drilling with the pointed and cylindrical tool was not performed thoroughly. Therefore, the paper novelty lies in the combined numerical and experimental study of gravity feed SACE drilling process that enhances the scientific knowledge related to tool shapes in gravity feed SACE drilling (Fig. 4).

\section{Thermal modeling}

A FEM transient thermal model was established to predict the MRR of the glass work material. The work material of dimensions $300 \times 300 \times 400 \mu^{3}$ was selected for developing the model as shown in Fig. 5. The soda-lime glass was chosen as work material, and its key properties used in

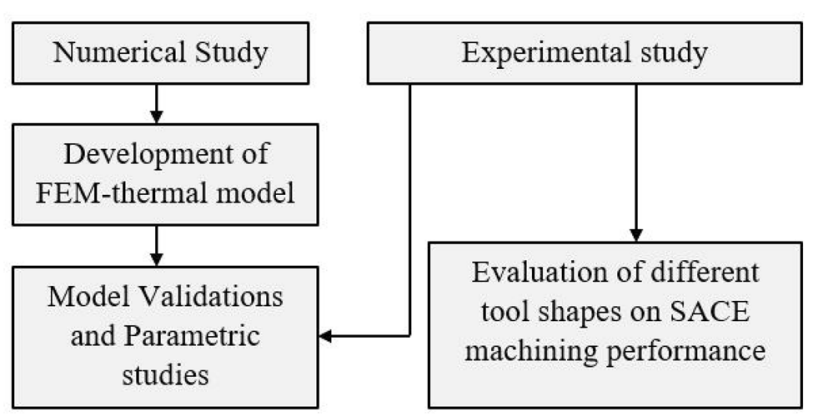

Fig. 4 Paper layout

FEM are highlighted in Table 1. The steps in the development of the FEM model in SACE are highlighted in Fig. 6.

\subsection{Assumptions}

For developing the thermal model, the following assumptions are used as referred from other studies $[33,34,36]$ :

- The properties of the glass work material are assumed to be isotropic.

- Only one spark at a time was assumed, and all the sparks are assumed similar. Gaussian heat energy was assumed within the spark and assumed uniform for all the sparks. 


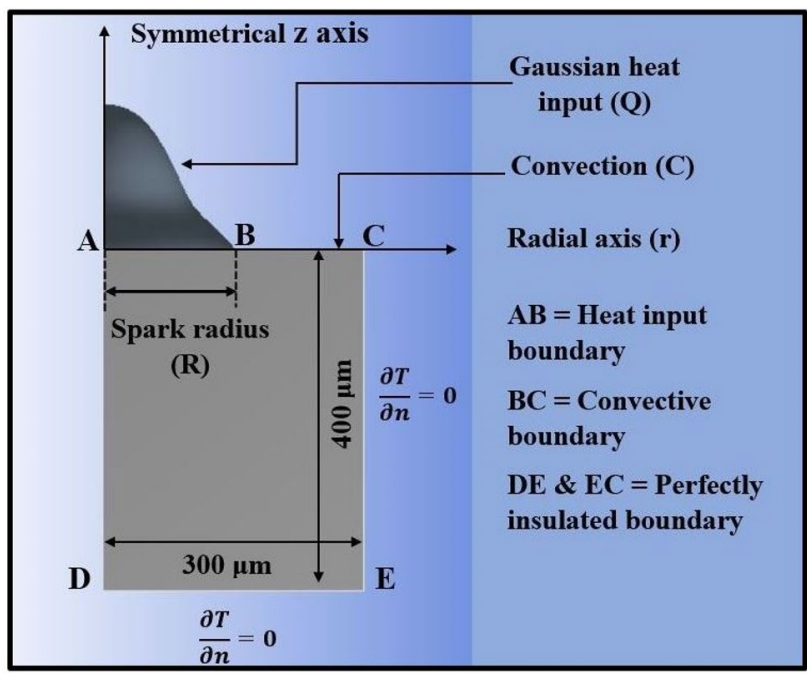

Fig. 5 FEM thermal model

- A spark radius of $150 \mu \mathrm{m}$ and a spark duration of $100 \mu \mathrm{s}$ were assumed for a single spark $[34,36]$.

- Energy transference to the work material $\left(E_{p}\right)$ of $20 \%$ was assumed.

- Any material above the work material melting temperature $\left(T_{m}\right)$ was assumed to be removed. The shape of the cavity removed was assumed to be hemispherical.

- The working conditions remain constant during the SACE machining process.

- Effect of tool wear, the formation of the recast layer, and drop in electrolyte level were neglected.

\subsection{Heat source}

Gaussian heat distribution was assumed within the spark region, and its expression is given as

$H=\frac{4.45 E_{p} V I}{\text { Areaofspark }} \exp \left\{-4.5\left\{\left(\frac{r}{R}\right)^{2}\right\}\right\}$ where $E_{p}$ is the energy transference energy, $V$ and $I$ are the critical current and voltage values, $r$ is the radial distance and $\mathrm{R}$ is the spark radius.

Energy transference of $20 \%$ was utilized in this study by referring to the study of Basak and Ghosh [9]. The current (I) values are obtained using Eq. (2) which is a function of electrolyte concentration (C). Several FEM studies utilized similar equations for developing the thermal model with SACE $[34,36]$ :

$I=3.2323 \times 10^{-5} C^{3}-0.0027056 C^{2}+0.091378 C+0.71429(\mathrm{NaOH})$

The spark radius of $150 \mu \mathrm{m}$ signifies that the effect of the Gaussian heat within the spark remains effective up to this distance. Thereafter, the convention takes place.

\subsection{Boundary conditions}

The initial work material temperature of the glass was assumed to be room temperature $\left(T_{0}\right)$, i.e., $T=T_{0}$ at $t=0$. Boundary $A B$ receives a Gaussian heat input $(H)$ as given in Eq. 1 over the work material top surface (Fig. 5). The effect

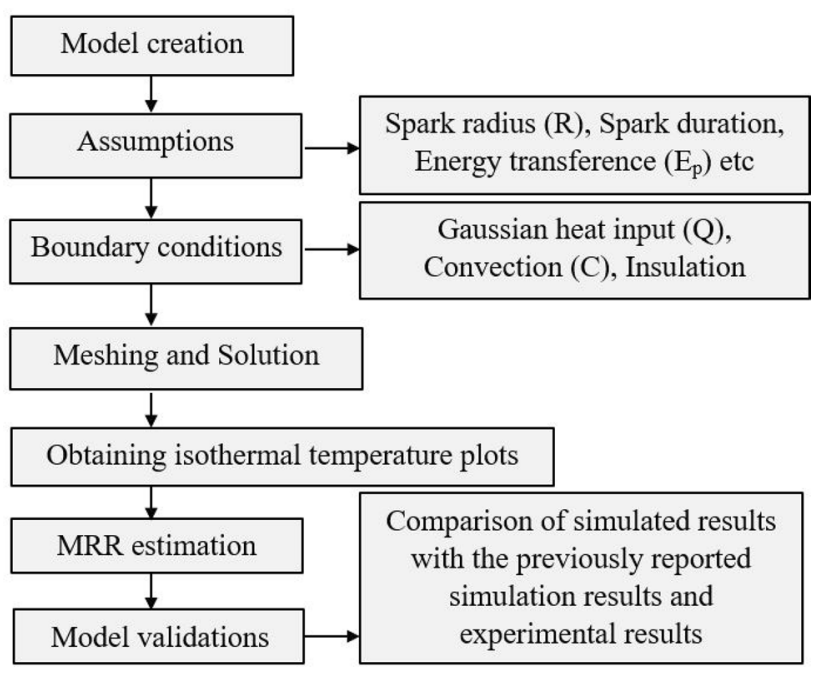

Fig. 6 Steps in the development of the FEM thermal model
Table 1 Soda-lime glass properties [34, 38]

\begin{tabular}{|c|c|c|c|}
\hline \multicolumn{2}{|c|}{$\begin{array}{l}\text { Typical mechanical, thermal, and electrical properties of soda- } \\
\text { lime glass }\end{array}$} & \multicolumn{2}{|c|}{$\begin{array}{l}\text { Chemical composition of a soda- } \\
\text { lime Ggs }\end{array}$} \\
\hline Property & Value & Components & Percentage \\
\hline Density, $\rho\left(\mathrm{kg} / \mathrm{m}^{3}\right)$ & 2170 & $\mathrm{SiO}_{2}$ & 73 \\
\hline Young's modulus (GPa) & $68-72$ & $\mathrm{Na}_{2} \mathrm{O}$ & 15 \\
\hline Thermal conductivity, $k$ (W/m K) & 1.6 & $\mathrm{CaO}$ & 7 \\
\hline Melting temperature, $T_{m}(\mathrm{~K})$ & 1673 & $\mathrm{MgO}$ & 4 \\
\hline Specific heat, $C_{p}(\mathrm{~J} / \mathrm{kg} \mathrm{K})$ & 670 & $\mathrm{Al}_{2} \mathrm{O}_{3}$ & 1 \\
\hline Convective heat coefficient, $h\left(\mathrm{~W} / \mathrm{m}^{2} \mathrm{~K}\right)$ & 10,000 & & \\
\hline
\end{tabular}


of heat on other boundaries ( $D E$ and $C E$ ) was negligible and considers perfectly insulated (Eq. 3). No heat transfer takes place across these boundaries. For $A D$, when viewing in $3 \mathrm{D}$, the heat generated would be symmetrical.

$\frac{\partial T}{\partial n}=0, t \geq 0, n$ is normal to the boundary

The remaining top boundary over the top work material, i.e., $B C$, releases heat to the atmosphere and considers as the convective boundary. It is expressed as

$C=h\left(T-T_{0}\right)$

where $h$ is a convective coefficient, $T$ is work material temperature, and $T_{0}$ is room temperature.

\subsection{Material removal criteria and estimation}

The MRR of glass was predicted by utilizing the plots of the temperature distributions obtained within the work material. The material removal in SACE is proportional to the rise in the work material temperature. Therefore, the MRR was assumed to be removed when work material temperature $(T)$ becomes higher than the work material melting temperature $\left(T_{m}\right)$. It is written as

$T>T_{m}$

The isothermal plots of temperature are identified at the melting temperature, and any material above this temperature was assumed to be removed. The schematic diagram for material removal criteria due to a single spark is shown in Fig. 7. The amount of volume removed due to a single spark was estimated by determining the volume of the cavity obtained along the melting temperature line, expressed as
$V_{m}=\iiint r_{m} z_{m} \theta d r d z d \theta=\frac{2}{3} \pi r_{m}^{2} z_{m}$

The volume of the material removed per unit time is expressed as

$V_{T}=V_{m} \times($ total number of sparks per unit time $)$

The final MRR is calculated as

$M R R=V_{T} \times($ work material density $(\rho))$

\section{Experimental details}

\subsection{Experimental setup}

The experiments were performed on the developed experimental setup which was integrated into a vertical milling machine (Make: Fridge Werner Type-FV-1) as shown in Fig. 8. A gravity-assisted tool feed was utilized for drilling the micro-holes. Gravity feed was achieved by using an additional weight of 'slider' (tool holding device is attached to this part) which moves relatively (or slides) with respect to 'connector' as shown in Fig. 9. The connector is attached to the machined spindle (Fig. 8, zoomed left top corner). The slider moves downward due to gravity and so the tool. Both the work material and the tool electrode (cathode) were made to be in physical contact with each other by using a machine $\mathrm{X}, \mathrm{Y}$ and $\mathrm{Z}$ hand wheels having a resolution of $0.05 \mathrm{~mm}$, respectively.

The electrolytic cell was made of polycarbonate which was filled with electrolyte. A regulated and continuous DC power supply fabricated in house with voltage and the current range of $(0-80 \mathrm{~V}, 10 \mathrm{~A})$ was applied for initiating the spark at the tooltip. The work material was fixed

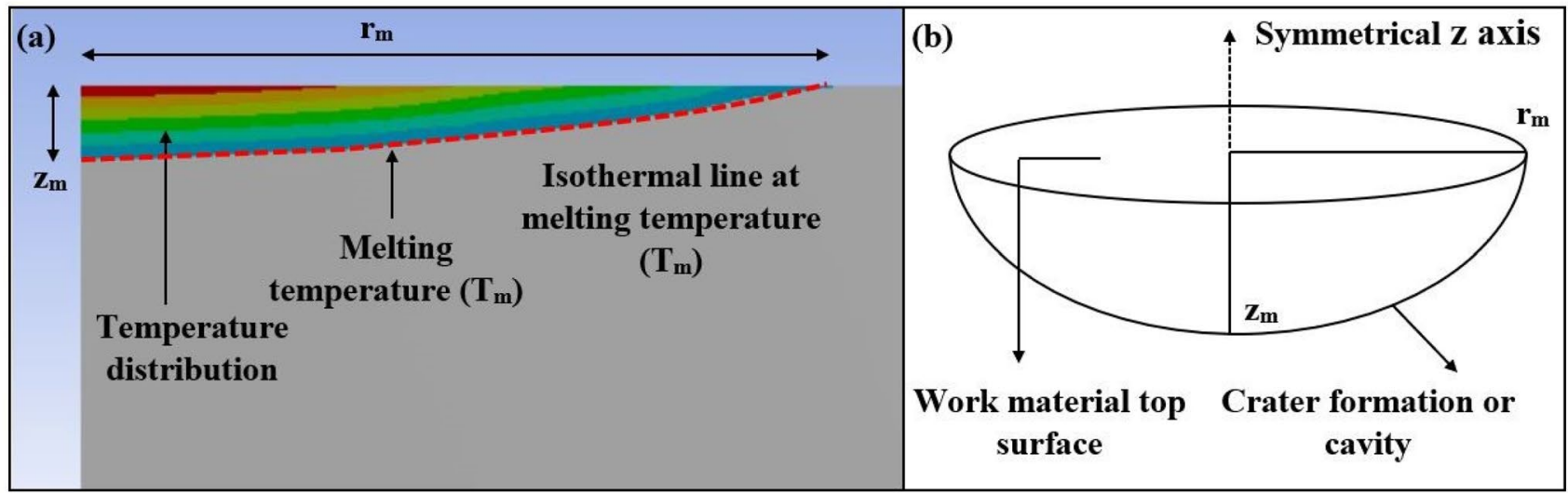

Fig. 7 Material removal criteria: a temperature distribution, $\mathbf{b}$ volume removed 
Fig. 8 Developed experimental setup [3]

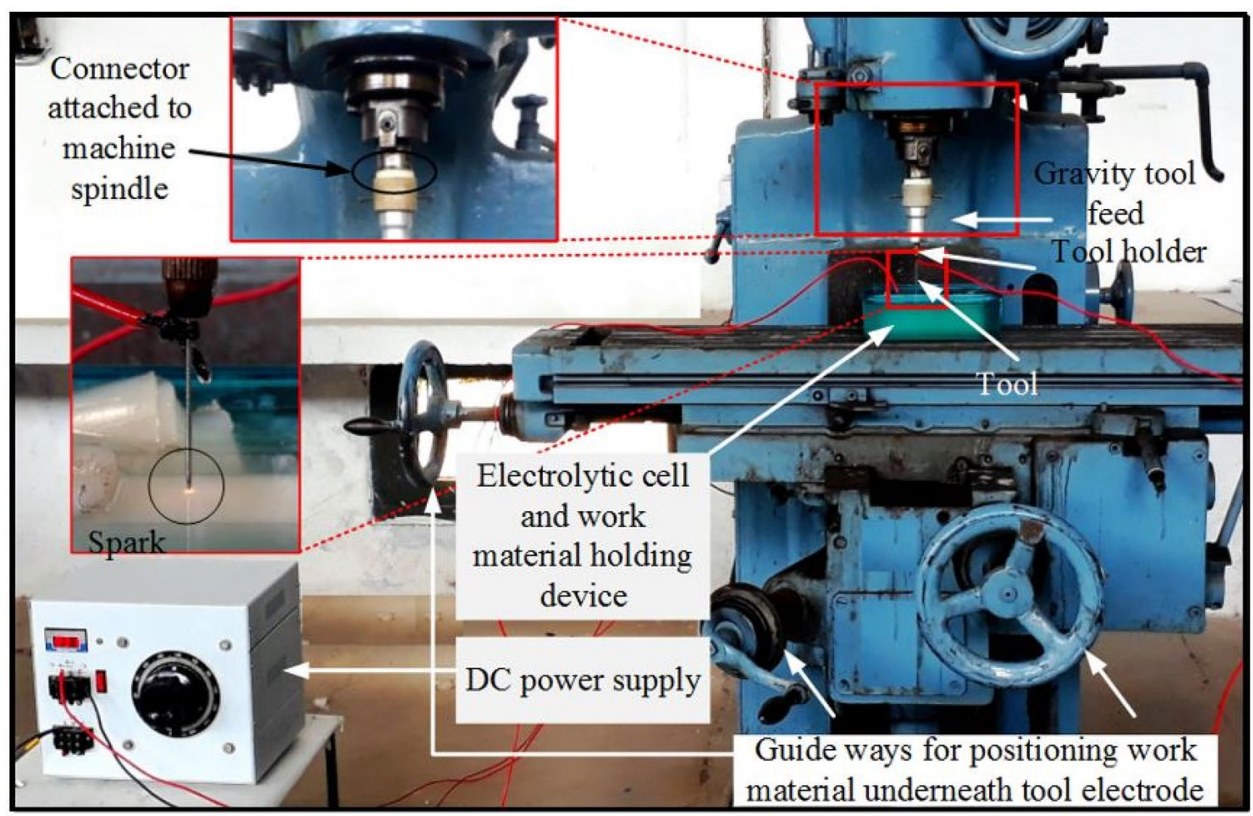

Fig. 9 Gravity feed device: a CAD model, $\mathbf{b}$ fabricated

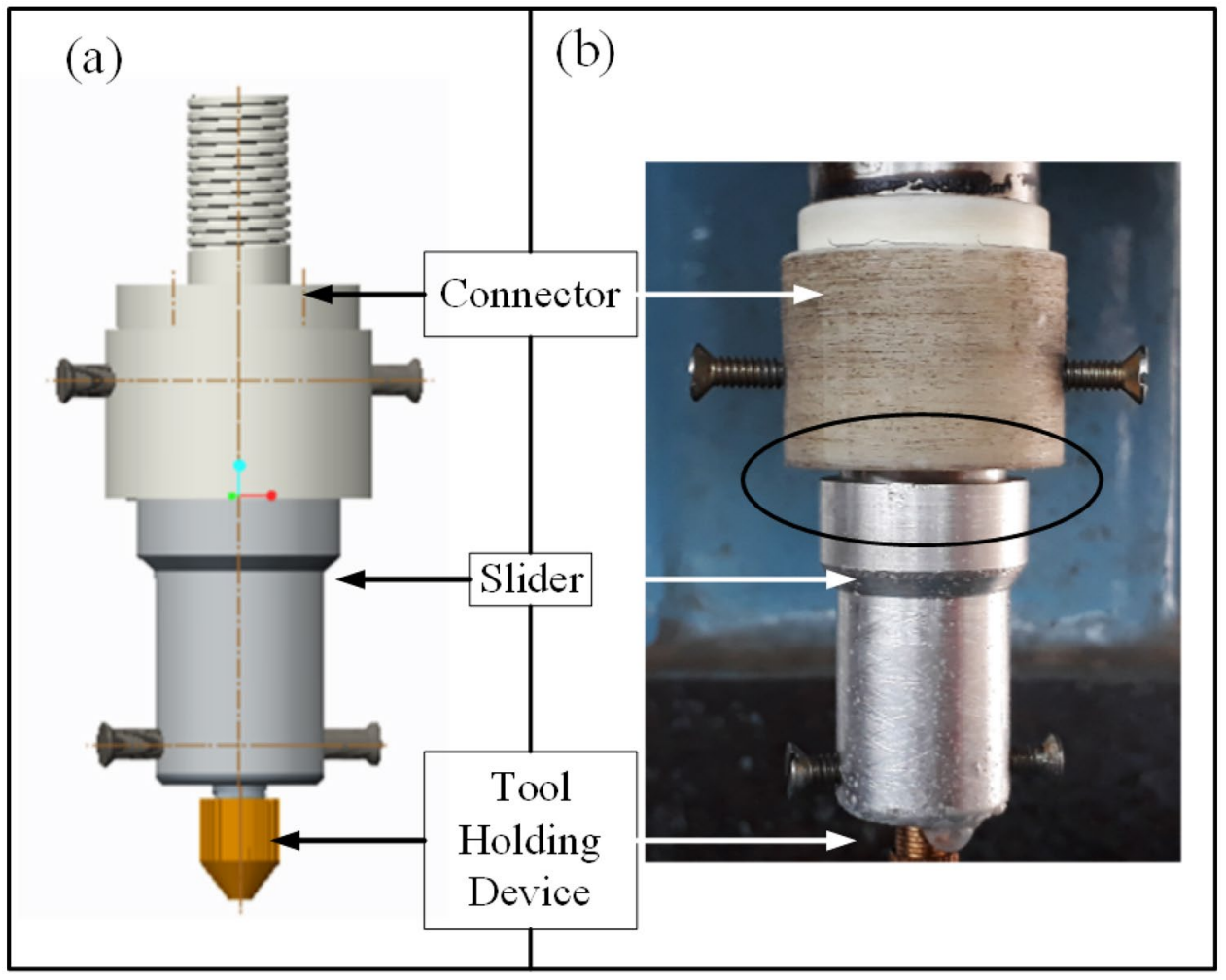

on non-reactive fixture inside the electrolytic cell, and the electrolyte level was measured by the dip of the tool inside the electrolyte. The soda-lime glass was chosen as a work material with a $1 \mathrm{~mm}$ thickness. Different shapes tool electrodes, i.e., pointed tip and cylindrical, were used for machining micro-holes on the glass work material. The tools were made up of stainless steel and have a radius of
$0.5 \mathrm{~mm}$. Experiments were performed using one-factorat-a-time (OFAT) approach. Figure 10 shows the shape and size of the different tool electrodes used in this study. Additionally, helical tool (drill bit) was also used to produce micro-holes, but the poor hole quality was observed due to the non-uniform spark consistencies with the helical tool (Fig. 11a). Providing rotation to the tool is one such 


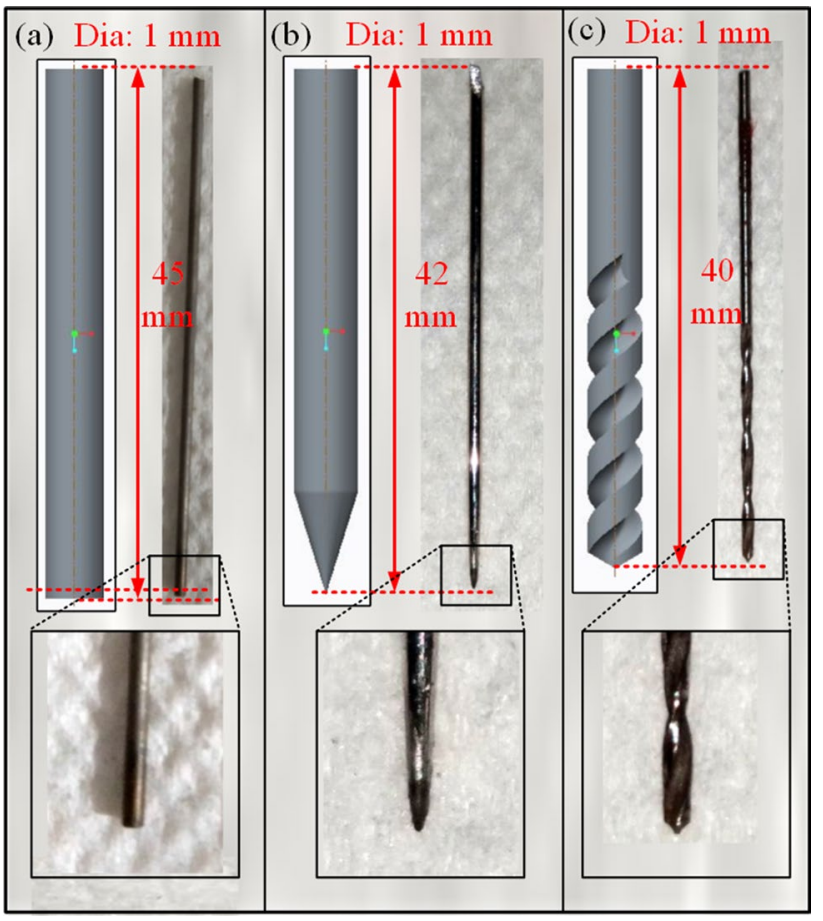

Fig. 10 Different tool shapes used in this present study: a cylindrical, b pointed, c helical

method that enhances the hole quality in terms of circularity. A rotation of $350 \mathrm{rpm}$ was provided to the helical tool which improves its circularity. However, severe damage to the work material was observed that may be due to the tool contact with the work material (Fig. 11b). Numerous studies were reported the tool rotational effect in SACE consists of constant tool feed method $[39,40]$. Thereafter, a cylindrical and pointed tool was used for further study in the gravity-assisted micro-hole drilling process.

\subsection{Machining procedure and measurements}

The experiments were performed to analyze the effect of different tool shapes on (a) MRR, (b) hole entrance diameter $\left(D_{\text {ent }}\right)$, (c) machining depth, (d) aspect ratio, (e) thermal cracks, and (f) machining time for constant drilling depth. Sodium hydroxide $(\mathrm{NaOH})$ was used as an electrolyte, and its pellets were mixed in water to obtain the different electrolyte concentrations. For $20 \mathrm{wt} . \%, 200$ $\mathrm{gm}$ of $\mathrm{NaOH}$ pellets is mixed and stirred in $1 \mathrm{~L}$ of water. $\mathrm{NaOH}$ electrolyte was used because the chemical etching process of the glass work material requires the presence of $\mathrm{OH}^{-}$ions on its top surface. A noticeable etching was observed with the utilization of $\mathrm{NaOH}$ electrolyte $[3,8,25]$. The chemical reaction of the $\mathrm{NaOH}$ electrolyte with a glass surface is given as

$2 \mathrm{NaOH}+\mathrm{SiO}_{2} \rightarrow \mathrm{Na}_{2} \mathrm{SiO}_{3} \downarrow+\mathrm{H}_{2} \mathrm{O}$

The other details of machining conditions are highlighted in Table 2. The MRR was computed by measuring the weight of the work material before and after machining which is given as

$M R R=\left(\left(w t_{1}-w t_{2}\right) / t\right)$

where $w t_{1}=$ weight before machining $(\mathrm{mg}), w t_{2}=$ weight after machining and $t=$ time in minutes. A weighing machine (model: CAY220, make: CAS corporation) with the least count of $0.0001 \mathrm{~g}$ was used for measurement. An average of three measurements was taken. The state of the machined holes was analyzed from the tool entry side by using a stereomicroscope (model: Stemi-305 Trino, make: Carl Zeiss) equipped with Zen blue software for studying hole entrance diameter, machining depth, aspect ratio, and thermal cracks.
Fig. 11 Micro-hole drilled with a helical tool: a without rotation, $\mathbf{b}$ with rotation

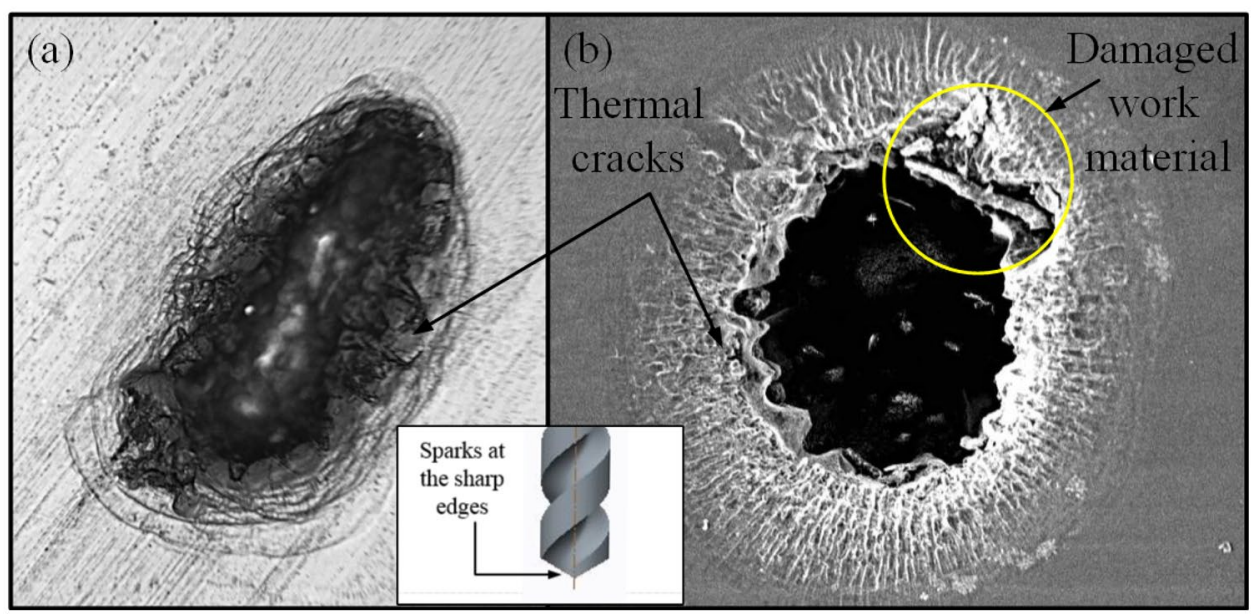


Table 2 Machining conditions used for micro-hole drilling studies

\begin{tabular}{|c|c|c|c|c|}
\hline \multirow[t]{2}{*}{ Different studies } & \multicolumn{2}{|c|}{ Variable parameter } & \multicolumn{2}{|l|}{ Constant parameters } \\
\hline & Voltage (V) & $\begin{array}{l}\text { Electrolyte con- } \\
\text { centration (wt.\%) }\end{array}$ & Parameter & Value \\
\hline Experimental study for model verification & 45 & $20-25-30-35$ & Electrolyte & $\mathrm{NaOH}$ \\
\hline Tool shape effect on MRR & $45 \& 50$ & $20-25-30$ & Machining time & $2 \mathrm{~min}$ \\
\hline Tool shape effect on hole entrance diameter & $45 \& 50$ & $20-25-30$ & Electrolyte temperature & $50^{\circ} \mathrm{C}$ \\
\hline Tool shape effect on machining depth and aspect ratio & $45 \& 50$ & $20-25-30$ & Cathode and anode material & Stainless steel \\
\hline Tool shape effect on thermal cracks & $45 \& 50$ & $20-25-30$ & Inter-electrode gap (IEG) & $30 \mathrm{~mm}$ \\
\hline Tool shape effect on machining time & 45 & $20-25$ & Electrolyte level & $1 \mathrm{~mm}$ (approx.) \\
\hline
\end{tabular}

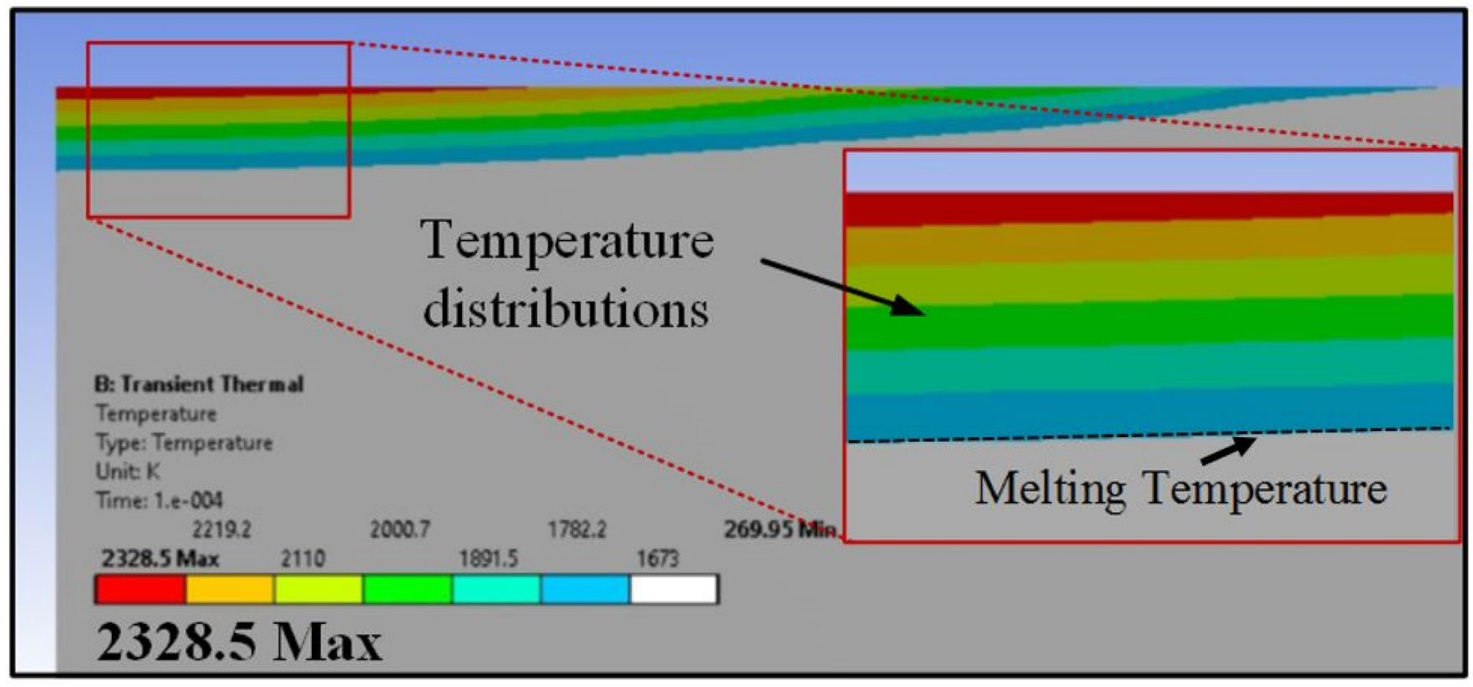

Fig. 12 Temperature distributions within the work material

\section{Results and discussion}

\subsection{Model validations}

A FEM-based thermal model was established to analyze the MRR of glass work material by acquiring the distribution plots of temperature as shown in Fig. 12. The developed model was meshed using the tetrahedron mesh methods before proceeding to the solver. The model meshing was performed to acquire more accuracy in the results. The temperature at each node was solved by ANSYS solver. The temperature distributions obtained along the depth of the work material in the FEM study were compared with the temperature distributions of the Goud model [36] as shown in Fig. 13. The variation of the temperature distribution was observed similar, yet some differences in the temperature values were also noticed because of different thermal heat input applications. Moreover, to assess the validations of the

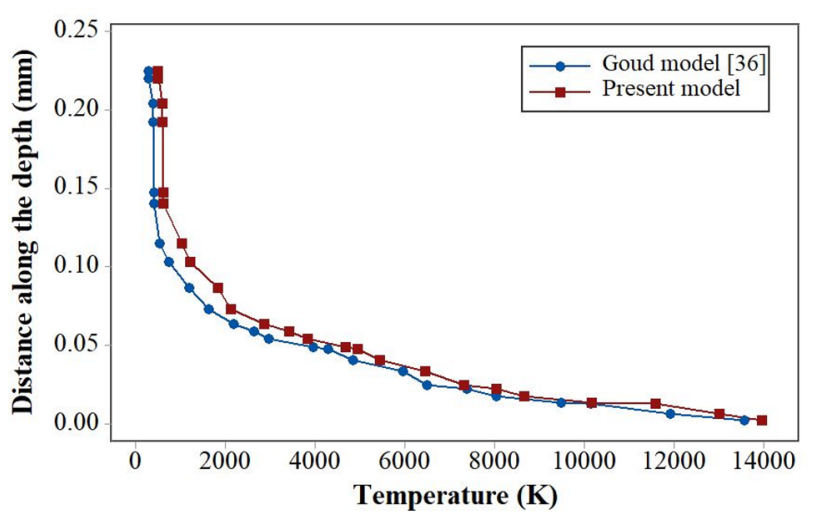

Fig.13 Temperature distributions along the work material depth

developed model, the predicted MRR was compared with the previously reported simulations and experimental results at different $\mathrm{NaOH}$ concentrations as shown in Fig. 14a. It was perceived that the MRR variation was 

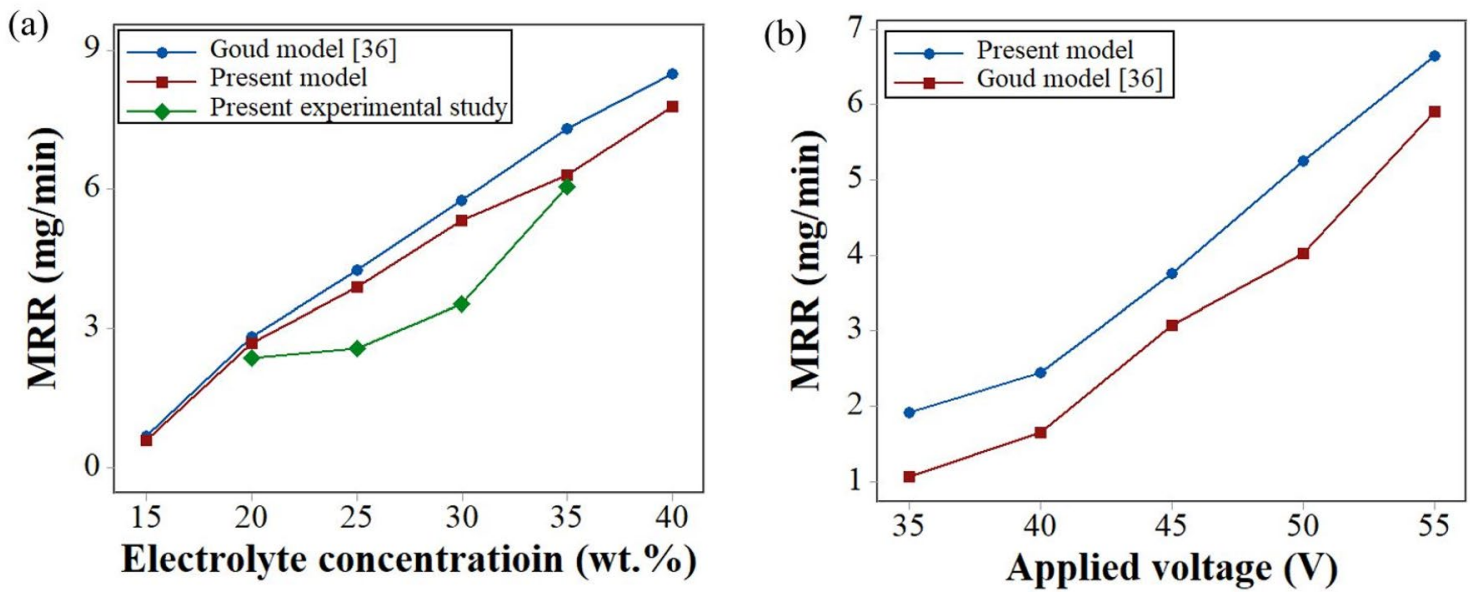

Fig. 14 Comparison of MRR variation at a different electrolyte concentrations, $\mathbf{b}$ different applied voltages

similar in all the cases as seen from the figure. However, a difference in the values also observed when compared to the Goud model. It was seen because Goud utilized a 3D Gaussian heat input, while the present study utilized a 2D heat input. A fair agreement was observed between the experimental and predicted MRR. A maximum difference of $1.39 \mathrm{mg} / \mathrm{min}$ in MRR was found at $35 \mathrm{wt} . \%$ due to the different assumptions made in the FEM model such as spark radius and energy transference.

\subsection{Effect of electrolyte concentration on MRR}

It was noticed that the MRR of the soda-lime glass improves with the increase in the concentration (Fig. 14a). The rate of formation of hydrogen bubbles at the tool electrode accelerates with the concentration increase due to enhanced electrolyte conductivity. It raises the spark strength and increases the thermal energy transference into the machining area. Hence, an increase in MRR was acquired. Figure 15 illustrates the increase in input thermal energy over the work material with the increase in electrolyte concentration obtained through simulations. An increase of $5.69 \mathrm{mg}$ in predicted MRR was observed with the concentration increase from $15 \mathrm{wt} . \%$ to $35 \mathrm{wt} . \%$. The present experimental study revealed a similar trend with the FEM study of Goud.

\subsection{Effect of applied voltage on MRR}

Any increase in applied voltage results in the improvement in MRR because of the enhanced formation rate of the gas film. It increases the frequencies of the spark over the work material, and as a result, MRR was improved (Fig. 14b). An increase of $4.72 \mathrm{mg}$ in predicted MRR was noticed with the increase in voltage from 35 to $55 \mathrm{~V}$ at $35 \mathrm{wt} . \% \mathrm{NaOH}$ concentration. The trend of MRR predicted in this model was found to be in agreement with the trend of MRR predicted in the Goud model [36].

\subsection{Tool shape effect on MRR}

It was observed that tool shape significantly affects the MRR due to the different concentrations of spark intensities at the tool surface. It results in the formation of a gas film with varied thickness, thereby giving variable machining performance. A schematic diagram of spark (or discharge) concentration and electrolyte flow for different tool shapes is shown in Fig. 16. Under the same machining conditions, the MRR was found maximum in the case of a pointed tip tool electrode when compared to the cylindrical tool electrode. Enhancement in electrolyte flow due to reduced tool contact area with the work material at higher machining depth, in comparison with cylindrical tool electrode, also contributed to the increase in MRR with improved drilling depth. Figure 17 shows the graphical plot of MRR at different electrolyte concentrations and different machining time for both the tool electrodes. An improvement of $16.74 \%$ in MRR was observed at $20 \mathrm{wt} . \%$ with the utilization of the pointed tip tool electrode in comparison with the cylindrical tool electrode due to enhanced electrolyte flow and spark consistency.

The parametric study revealed that experimental MRR increases with the increase in electrolyte concentration, applied voltage, and machining time for both the electrodes. With increasing concentration and applied voltage, the rate of formation of hydrogen bubbles increases, and a quick formation of the gas film was obtained. Hence, more spark frequency over the work material was observed which increases the thermal energy transference. As a result, high MRR was acquired. An increase of $0.20 \mathrm{gm}$ and 


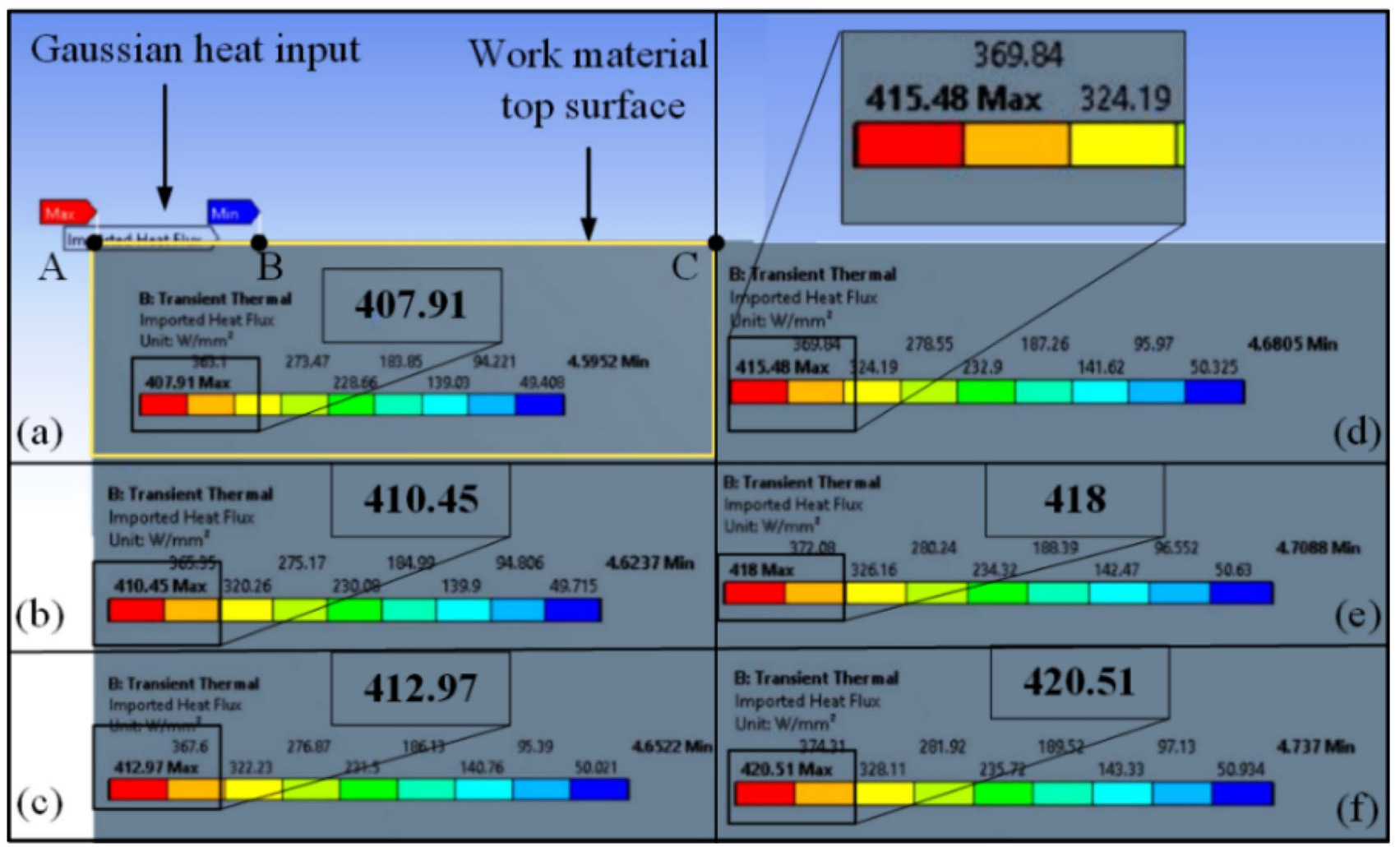

Fig. 15 Heat input energy at a 15 wt.\%, b 20 wt.\%, c 25 wt.\%, d 30 wt.\%, e 35 wt.\%, f 40 wt.\%

(a)

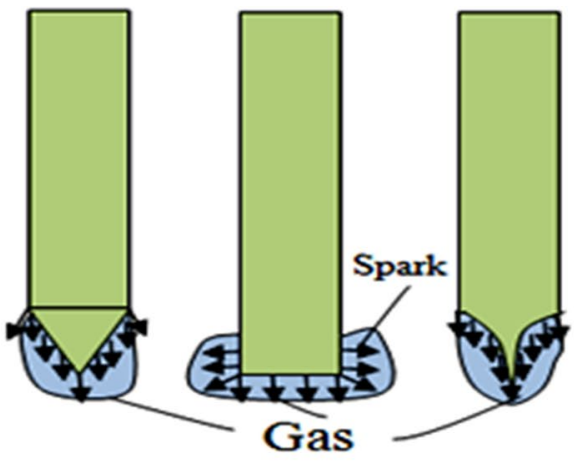

(b)

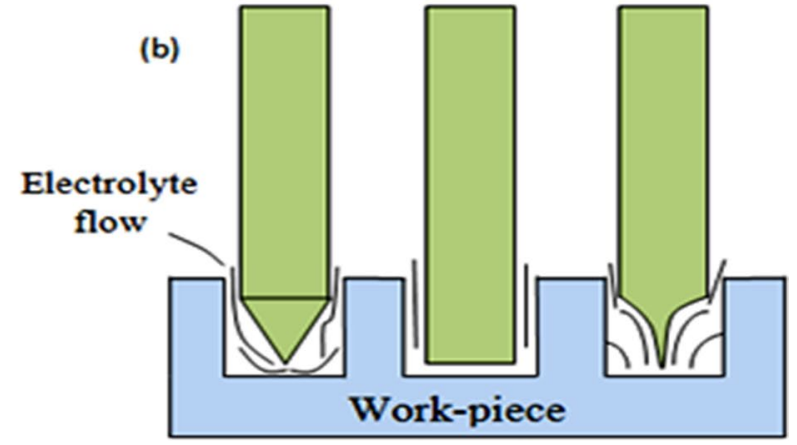

Fig. 16 a Spark concentration. b Electrolyte flow in pointed, cylindrical, and tapered tip tool electrode (left to right)

$0.96 \mathrm{gm}$ in material removal was observed when electrolyte concentration was increased from $20 \mathrm{wt} \%$ to $25 \mathrm{wt} \%$ and $25 \mathrm{wt} \%$ to $30 \mathrm{wt} \%$, respectively. An increase of $1.06 \mathrm{mg}$ was observed at $20 \mathrm{wt} \%$ when the voltage increases from 45 to $50 \mathrm{~V}$ (Fig. 17b).

MRR was found to be increased with the increase in machining time as shown in Fig. 17a. It was explained that the heat energy transference to the work material increases with the increase in machining time that causes an increase in MRR.

\subsubsection{Tool shape effect on hole entrance diameter}

It was observed that a cylindrical tool produced enlarged hole entrance diameter when compared to the pointed tip tool. Any increase or decrease in hole entrance diameter was the result of spark frequencies from the tool surface, caused by the gas film, that depends upon electrolyte availability. The pointed tool electrode produces more spark consistencies underneath the tool tip thereby giving more stable gas film when compared to a cylindrical 

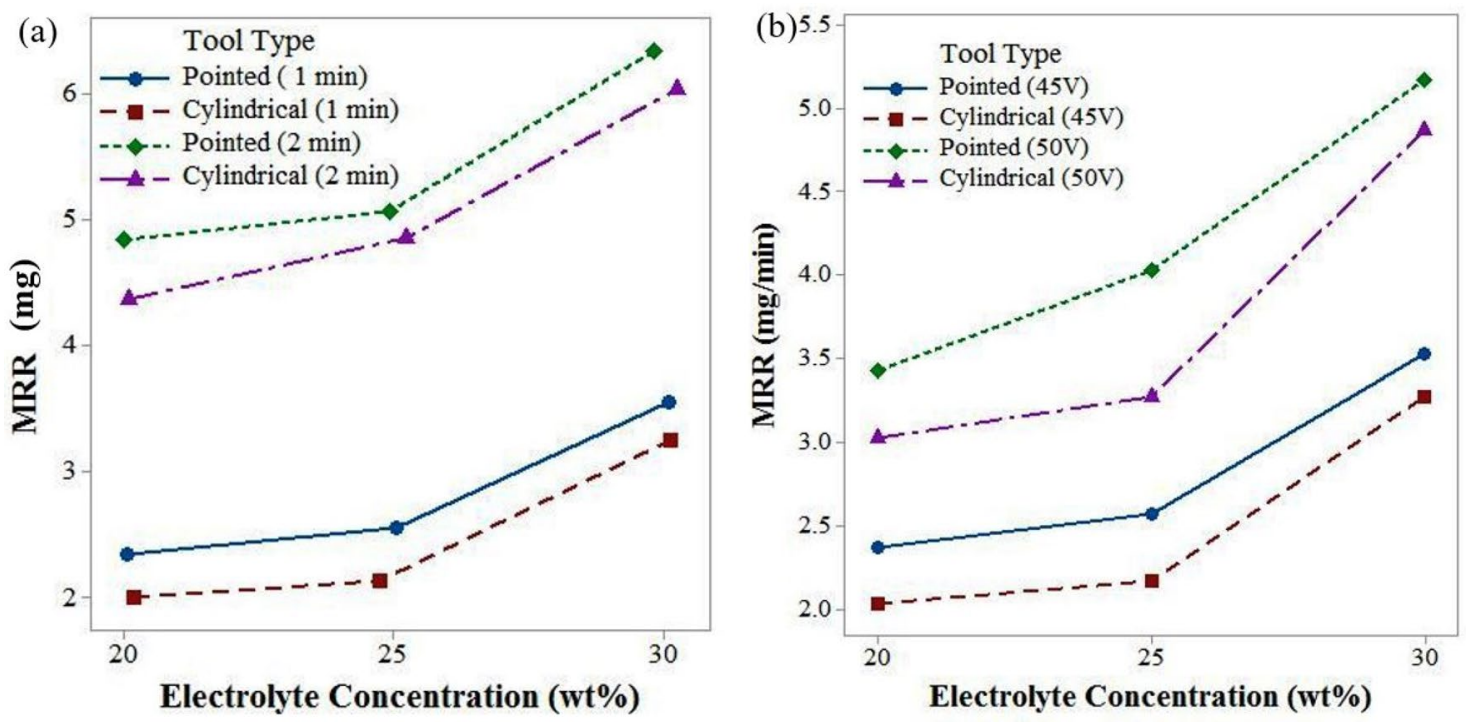

Fig. 17 Comparison of MRR for different tool shapes at different electrolyte concentrations: a different machining time, b different applied voltages

tool that produces spark only at the circular rim. It was noteworthy to see that undesirable sparks were more in the case of cylindrical tools (Fig. 16a) which increased the hole entrance diameter. Figure 18 demonstrates the comparison of hole entrance diameter for both the tool electrodes at different machining conditions when observed under similar magnifications. The hole entrance diameter increases with the increase in both the electrolyte concentration and applied voltage. An increase of $11.76 \%$ with a pointed tool and an increase of $22.34 \%$ with a cylindrical tool were found with the increase in concentration from $20 \mathrm{wt} . \%$ to $25 \mathrm{wt} . \%$ and voltage from 45 to $50 \mathrm{~V}$, respectively. The reason thereof was seen as the greater number of sparks takes place from the tool sides at higher levels of electrolyte concentration and applied voltage. The amount of thermal energy transference was
Fig. 18 Hole entrance diameter obtained with a pointed tool at 20 wt. $\%, 45 \mathrm{~V}$; b cylindrical tool at 20 wt. \%, $45 \mathrm{~V}$; c pointed tool at $25 \mathrm{wt} . \%, 50 \mathrm{~V}$; d cylindrical tool at $25 \mathrm{wt} . \%, 50 \mathrm{~V}$

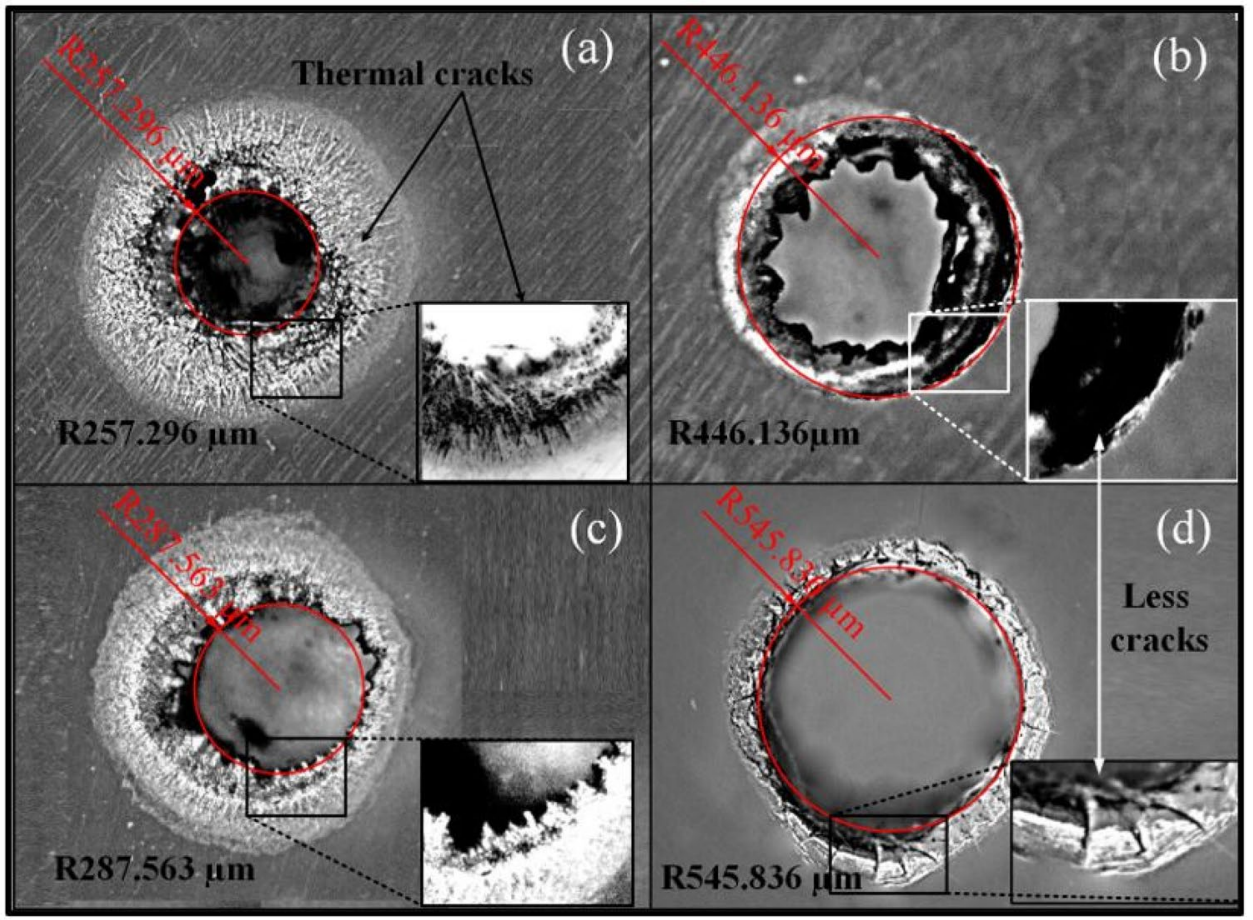


proportional to the $\mathrm{OH}$ concentration that improves with the concentration increase $[8,20]$. Also, an enhanced chemical etching action was seen at the micro-hole edge that causes the increase in hole entrance diameter.

\subsection{Tool shape effect on machining depth and aspect ratio}

The plot of machining depth at different electrolyte concentrations for a pointed and cylindrical tool is given in Fig. 19. The pointed tool produced micro-holes with higher machining depth due to the availability of the electrolyte. An increase of $18.49 \%$ was observed in depth at 30 wt.\% and $50 \mathrm{~V}$ with a pointed tool. With the increase in machining depth, the availability of the electrolyte becomes difficult in case of a cylindrical tool, and as a result, less material was removed. Hence, low machining depth was obtained. The machining depth improves with the

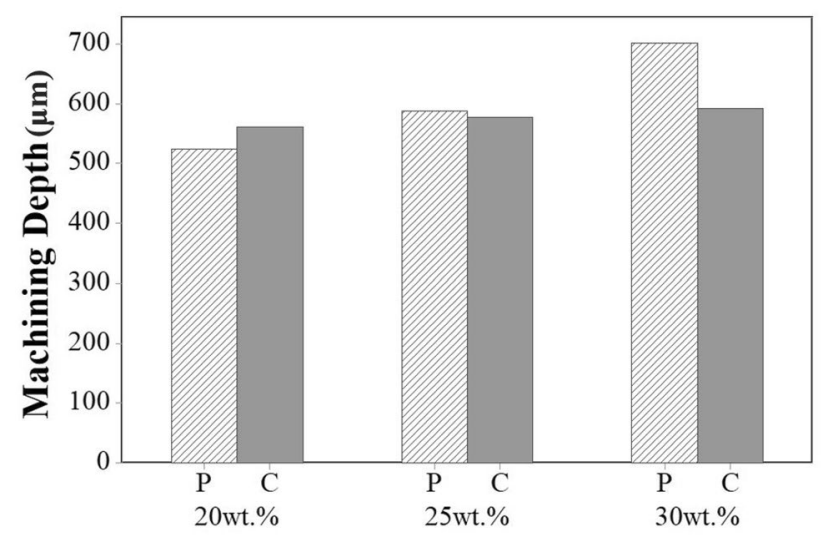

Fig. 19 Machining depth of micro-holes obtained with pointed (P) and cylindrical (C) tool at different electrolyte concentrations increment in electrolyte concentration because more sparks and etching can be obtained with the tool penetration inside the work material (Fig. 19). Figure 20 compares the cross-sectional microscopy images of the machining depth with pointed and cylindrical tool.

It was important to see that as the tool moves downward with increasing machining depth, the hole entrance becomes more exposes to the sparks due to prolonged interaction. It enlarges the hole entrance diameter and affects the hole aspect ratio. The plot of aspect ratio for both the tools at different electrolyte concentrations and the applied voltage is shown in Fig. 21. The aspect ratio was calculated as the ratio of machining depth (d) to the average diameter (D). The average diameter was the average of the hole entrance diameter $\left(D_{\text {ent }}\right)$ and hole exit diameter $\left(D_{\text {ext }}\right)[39]$. Since

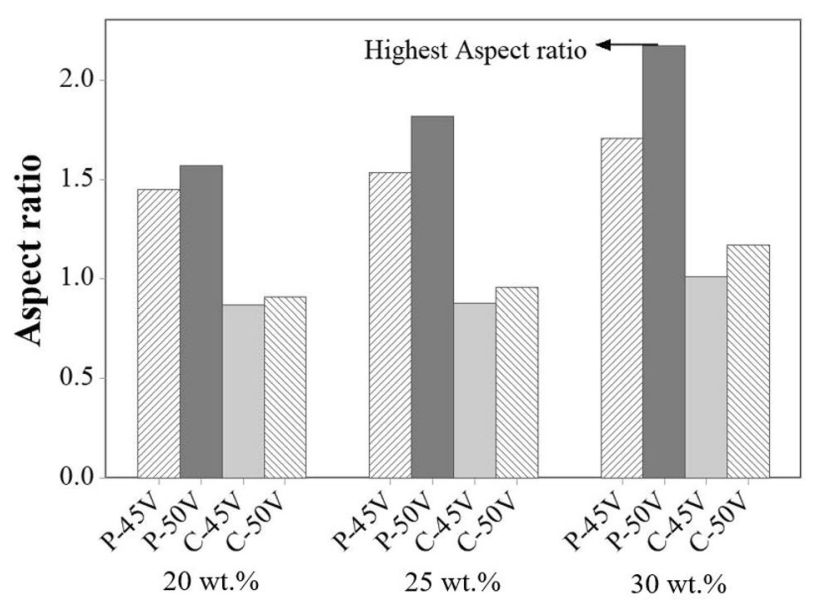

Fig. 21 The aspect ratio of micro-holes obtained with pointed (P) and cylindrical (C) tool at different electrolyte concentrations

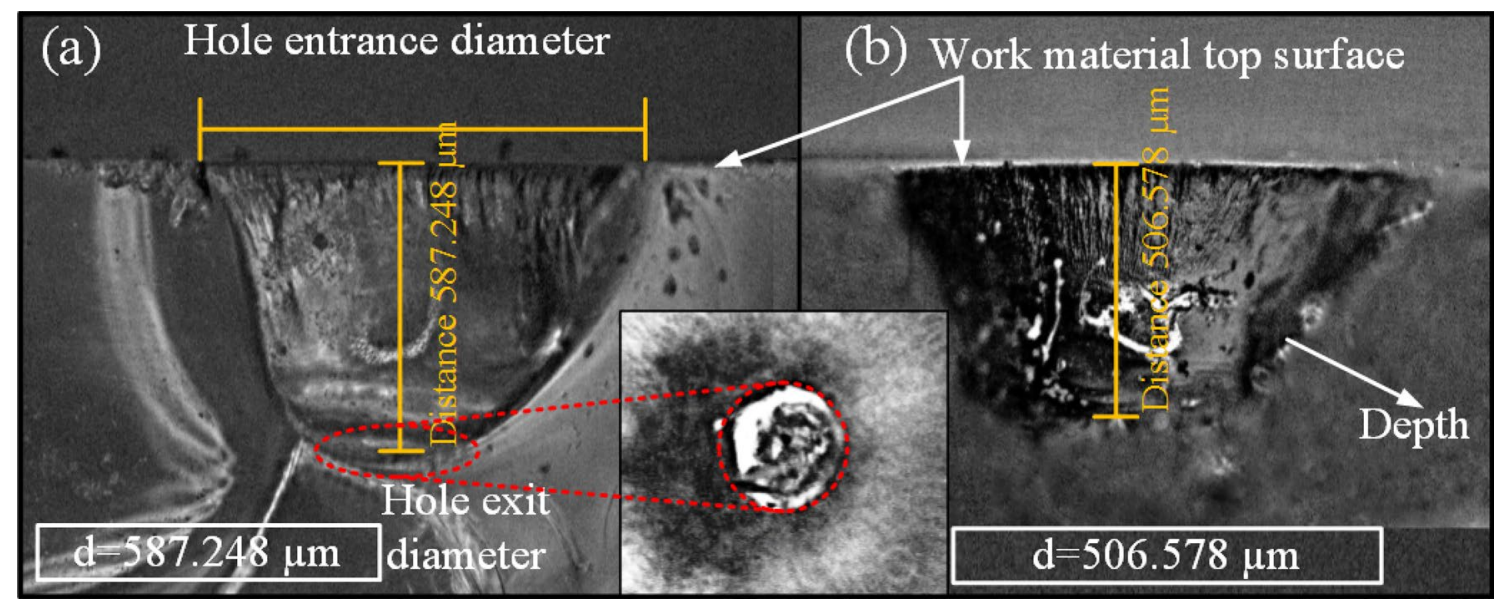

Fig. 20 Cross-sectional view of micro-holes obtained at $25 \mathrm{wt} . \%$ and $45 \mathrm{~V}$ with a pointed tool and $\mathbf{b}$ cylindrical tool 
the increase in hole entrance diameter was more compared to the increase in hole exit diameter in SACE drilling, more electrolyte was available at the work material top surface compared to electrolyte within the hole. Therefore, the average diameter was utilized for computing aspect ratio (AR) as given as

Aspect ratio $(\mathrm{AR})=(d / D)$

where $d$ is machining depth, and $D$ is $\left(\left(D_{\text {ent }}+D_{\text {ext }}\right) / 2\right)$. Since the pointed tool produced large machining depths and reduced hole entrance diameter, it was observed that high aspect ratio micro-holes were produced with a pointed tool (Fig. 21). It was depicted that aspect ratio improves with the increase in electrolyte concentration due to the increase in the micro-hole depth. The maximum aspect ratio of the micro-hole was achieved at a higher level of electrolyte concentration (25 wt.\%) and applied voltage (50 V) used in this study. The cross-sectional view of the micro-hole with the highest aspect ratio is shown in Fig. 22.

\subsection{Tool shape effect on thermal cracks}

Thermal cracks at the hole entrance were the result of tool physical contact with the work material under gravity-assisted tool feed which causes direct damage to the work material. More thermal cracks were observed at the edge of a micro-hole entrance with the application of the pointed tool electrode in comparison with the cylindrical tool electrode as shown in Fig. 18. It may be explained due to the increased frequency of the sparks at the top surface with the replenishment of the electrolyte as a pointed tool moves downward. On the contrary, as the cylindrical tool moves downward with the increasing machining depth, the more accumulation of the gas bubbles was observed at the top surface and so the chemical etching at the micro-hole edge. It causes a decrease in thermal cracks. Thermal cracks were found to be increased at the micro-hole edge with the increase in both the electrolyte concentration and applied voltage. It increases the thermal energy input to the work material, resulting more thermal cracks. Figure $18 \mathrm{~b}$ and $d$ shows the increase in thermal cracks (zoomed) with the increase in concentration from 20 to $25 \mathrm{wt} . \%$ and
Fig. 22 Micro-hole obtained at 30 wt. $\%$ and 50 V. a Hole entrance diameter. $\mathbf{b}$ Hole exit diameter. c Machining depth. d Schematic diagram for aspect ratio

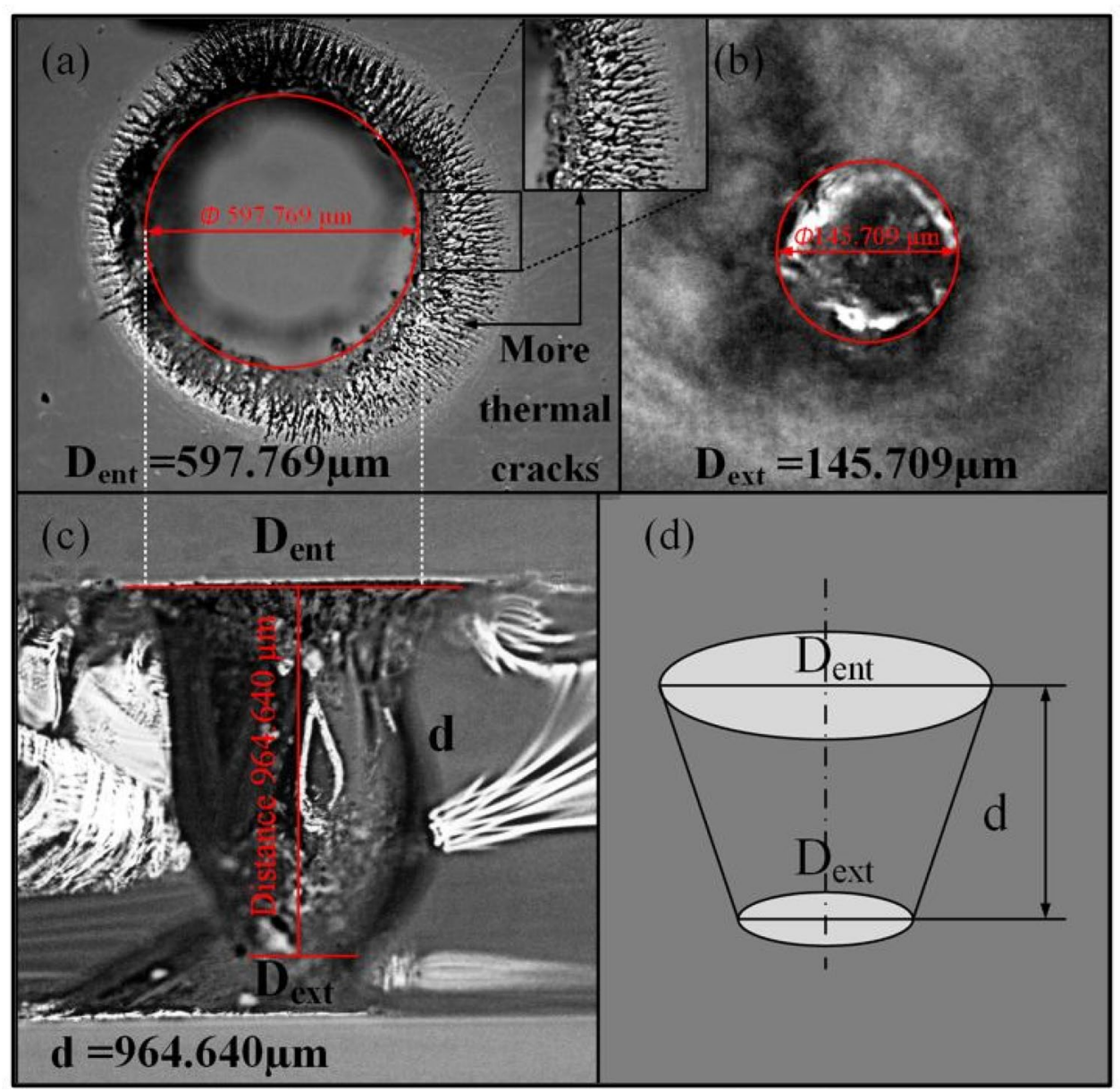


increase in voltage from 45 to $50 \mathrm{~V}$ for a cylindrical tool. Similar observations were seen between Figs. 18a and 22a that an increase in concentration from 20 to $30 \mathrm{wt} . \%$ produced more thermal cracks.

\subsection{Tool shape effect on machining time for drilling $1000 \mu \mathrm{m}$ constant machining depth}

The micro-holes with $1000 \mu \mathrm{m}$ machining depth were fabricated on the glass to investigate the machining time for different tools. Machining time was found minimum in case of pointed tip tool when compared to the cylindrical tool as shown in Fig. 23.

Different tool shapes give different machining time since the electrolyte flow was different which influences the chemical action during machining at higher depths (Fig. 5). Besides, the cylindrical tool results in the accumulation of more bubbles that hinders the electrolyte replenishment. It was seen due to close contact of the tool with the micro-hole wall which lengthens the gas film formation underneath the tool tip. Therefore, the retarded formation of gas film was observed due to reduced electrolyte supply with an increase in machining depth. As a result, machining time increases significantly with machining depth. On the contrary, the pointed tip tool prevents electrolyte hindrance, thus increasing the gas film formation by enhancing bubble growth at a uniform rate. This results in an improved

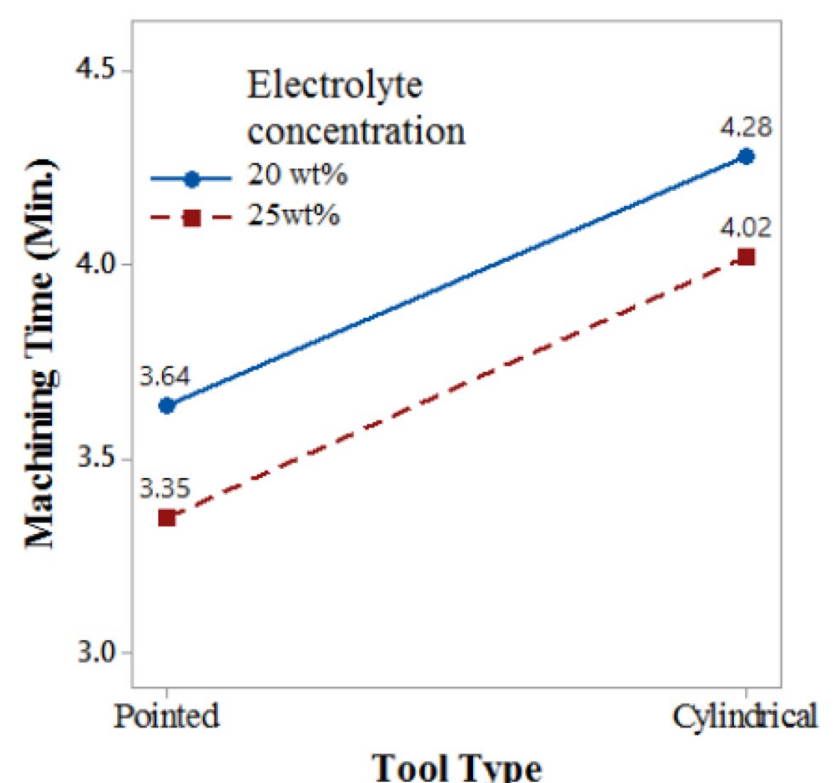

Fig. 23 Effect of tool shape on machining time for $1 \mathrm{~mm}$ machining depth machining rate of micro-holes in case of cylindrical tool for drilling $1 \mathrm{~mm}$ depth.

\section{Conclusion and future scope}

This present study attempted to develop a FEM-based thermal model for analyzing the MRR of soda-lime glass. The predicted results were compared with the experimental results and previously simulated results for validations. The evaluation of the effect of pointed and cylindrical tool on SACE performance in terms of MRR, hole entrance diameter, machining depth, aspect ratio, thermal cracks, and machining time was performed. Tool shape significantly affects the replenishment and flow of electrolyte during the gravity-assisted drilling process. The variable electrolyte flow produces different spark consistencies and thus gives variable machining. The conclusions drawn from the study are given underneath:

- The developed thermal model illustrates good consistencies with the experimental results and can be utilized for analyzing the MRR of different non-conductive materials.

- Simulation results show that MRR improves with the increase in both concentrations and applied voltage due to the increase in heat input energy.

- The pointed tip tool gives maximum MRR, while the cylindrical tool gives minimum MRR due to different spark concentrations and electrolyte flow. An improvement of $16.74 \%$ in MRR was observed with the utilization of the pointed tip tool electrode.

- Hole entrance diameter was found higher in the case of a cylindrical tool because of undesirable sparks at the tool circumference. It increases with the increase in machining depth due to prolonged exposure of the work material top surface to the sparks. Besides, a cylindrical tool produces better hole circularity with fewer thermal cracks.

- Higher machining depths and high aspect ratio of drilled micro-holes were acquired with the application of a pointed tool. An increase of $18.49 \%$ was observed in depth at $30 \mathrm{wt} . \%$ and $50 \mathrm{~V}$ with pointed tool. Rapid gas film formation occurs in pointed tip tools due to little hindrance to the electrolyte flow which promotes MRR at higher depths. It also improves the machining time for drilling a micro-hole with $1000 \mu \mathrm{m}$ machining depth. The machining time was decreased by $14.9 \%$ when compared to the cylindrical tool.

- The pointed tip tool enhances the SACE performance in terms of improved MRR, machining depth, aspect ratio, machining time, and reduced hole entrance diameter of micro-hole. 
Based on the study, it was suggested to drill a microhole in glass at lower values of concentration and voltage with a pointed tool. High concentration and voltage lead to an increase in hole entrance diameter and a greater number of thermal cracks. An increase in hole entrance diameter may cause hole taperness. Moreover, future works can be extended for studying different other tool shapes for the gravity-assisted drilling process alongside the optimization of the tool electrode parameters such as tool size and tool material.

\section{Compliance with ethical standards}

Conflicts of interest On behalf of all authors, the corresponding author states that there is no conflict of interest.

\section{References}

1. Wüthrich R, Hof LA (2006) The gas film in spark assisted chemical engraving (SACE) - a key element for micro-machining applications. Int J Mach Tool Manuf 46:828-835

2. Tolke RBH, Evans A, Rupp A, Gauckler JLM, Ludwig J (2012) Processing of Foturan glass-ceramic substrates for micro-solid oxide fuel cells. J Eur Ceram Soc 32L:3229-3238. https://doi. org/10.1016/j.jeurceramsoc.2012.04.006

3. Rajput V, Goud MM, Suri N M (2019) Performance Analysis on the Effect of Different Electrolytes during Glass Micro Drilling Operation Using ECDM. I-manager's Journal on Future Engineering and Technology 14(4): 5-13. https://doi.org/10.26634 /jfet.14.4.15788

4. Kurafuji H, Suda K (1968) Electrical discharge drilling of glass. Ann CIRP 16:415-419

5. Kubota M (1974) Proc. Int. Conf. Production Engineering (Tokyo) p5.1

6. Allesu K, Ghosh A, Muju MK (1992) Preliminary qualitative approach of a proposed mechanism of material removal in electrical machining of glass. Eur J Mech Eng 36:202-207

7. Tandon S, Jain VK, Kumar P, Rajurkar KP (1990) Investigations into machining of composites. Precis Eng 12:227-238

8. Basak I, Ghosh A (1997) Mechanism of spark generation during electrochemical discharge machining a theoretical model and experimental verification. J Mater Process Technol 62:46-53. https://doi.org/10.1016/0924-0136(95)02202-3

9. Basak I, Ghosh A (1997) Mechanism of material removal in electrochemical discharge machining a theoretical model and experimental verification. J Mater Process Technol 71:350-359. https://doi.org/10.1016/S0924-0136(97)00097-6

10. El-Haddad R, Wuthrich R (2010) A mechanistic model of the gas film dynamics during the electrochemical discharge phenomenon. J Appl Electrochem 40:1853-1858. https://doi.org/10.1007/ s10800-010-0141-7

11. Wuthrich R, Fascio V (2005) Machining of non-conducting materials using electrochemical discharge phenomenon - An overview. Int J Mach Tool Manuf 45:1095-1108. https://doi. org/10.1016/j.ijmachtools.2004.11.011

12. Lim HJ, Lim YM, Kim SM, Kwak YK (2001) Self-aligned micro tool and electrochemical discharge machining (ECDM) for ceramic materials. Proc SPIE 4416:348-353
13. Wüthrich R, Spaelter U, Wu Y, Bleuler H (2006) A systematic characterization method for gravity-feed micro-hole drilling in glass with spark assisted chemical engraving SACE. J Micromech Microeng 16:1891-1896. https://doi. org/10.1088/0960-1317/16/9/019

14. Maillard P, Despont B, Bleuler H, Wuthrich R (2007) Geometrical characterization of micro-holes drilled in glass by gravity-feed with spark assisted chemical engraving SACE. J Micromech Microeng 17:1343-1349. https://doi. org/10.1088/0960-1317/17/7/017

15. Zheng ZP, Su HC, Huang FY, Yan BH (2007) The tool geometrical shape and pulse-off time of pulse voltage effects in a Pyrex glass electrochemical discharge micro-drilling process. J Micromech Microeng 17:265-272. https://doi. org/10.1088/0960-1317/17/2/012

16. Wuthrich R, Fujisaki K, Couthy P, Hof LA, Bleuler H (2005) Spark assisted chemical engraving SACE in microfactory. J Micromech Microeng 276-280: https://doi.org/10.1088/0960-1317/15/10/ S04

17. Rajput V, Goud MM, Suri NM (2019) Experimental investigation to improve the removal rate of material in ECDM process by utilizing different tool electrode shapes. Int J Technical Innovation in Modern Engineering \& Science (IJTIMES) 5(2):333-341

18. Yang CK, Wu KL, Jung JC, Lee SMD, Lin JC, Yan BH (2011) Enhancement of ECDM efficiency and accuracy by spherical tool electrode. Int J Mach Tool Manuf 51:528-535. https://doi. org/10.1016/j.ijmachtools.2011.03.001

19. Sundaram M, Chen YJ, Rajurkar K (2019) Pulse electrochemical discharge machining of glass-fiber epoxy reinforced composite. CIRP Annals- Manufacturing Technology 68:169-172

20. Sarkar BR, Doloi B, Bhattacharya B (2017) Investigation on Electrochemical Discharge Micro-machining of Silicon Carbide. International Journal of Materials Forming and Machining Processes 4(2):16. https://doi.org/10.4018/IJMFMP.2017070103

21. Antil P, Singh S, Manna A (2018) Electrochemical discharge drilling of SiC Reinforced polymer matrix composite using Taguchi's grey relational analysis. Arab J Sci Eng 43(3):1257-1266

22. Manna A, Kundal A (2011) Micro-machining of nonconductive $\mathrm{Al}_{2} \mathrm{O}_{3}$ ceramic on developed TW-ECSM setup. International Journal of Manufacturing, Materials, and Mechanical Engineering 1(2):10. https://doi.org/10.4018/ijmmme.2011040103

23. Singh M, Singh S, Kumar S (2019) Experimental Investigation for Generation of Micro-Holes on Silicon Wafer Using Electrochemical Discharge Machining Process. Silicon 1-7: https://doi. org/10.1007/s12633-019-00273-8

24. Goud MM, Sharma AK, Jawalkar CS (2016) A review on material removal mechanism in electrochemical discharge machining $(E C D M)$ and possibilities to enhance the material removal rate. Prec Eng 45:1-17

25. Goud MM, Sharma AK (2017) On performance studies during micromachining of quartz glass using electrochemical discharge machining. J Mech Sci Technol 31:1365-1372

26. Rajput V, Pundir SS, Goud M et al (2020) Multi-Response Optimization of ECDM Parameters for Silica (Quartz) Using Grey Relational Analysis. Silicon. https://doi.org/10.1007/s12633-02000538-7

27. Kumar M, Vaishya RO, Oza AD, Suri NM (2019) Experimental investigation of wire-electrochemical discharge machining (WECDM) performance characteristics for quartz material. Silicon. https://doi.org/10.1007/s12633-019-00309-z

28. Rajput V, Goud MM, Suri N M (2020) Performance Analysis of ECDM Process Using Surfactant Mixed Electrolyte. In: Sharma V, Dixit U, Sørby K, Bhardwaj A, Trehan R (eds) Manufacturing engineering. Lecture Notes on Multidisciplinary Industrial Engineering. Springer, Singapore. https://doi. org/10.1007/978-981-15-4619-8_22 
29. Rajput V, Goud MM, Suri NM (2019) Study on effective process parameters: toward the better comprehension of ECDM process. Int J Modern Manufact Technol XI 2:105-118

30. Sharma JK, Parashar SK (2019) Experimental modal analysis using laser vibrometer and finite element modeling of milling machine arbor. SN Appl Sci 1:650. https://doi.org/10.1007/s4245 2-019-0664-4

31. Smolnicki M, Stabla P (2019) Finite element method analysis of fibre-metal laminates considering different approaches to material model. SN Appl Sci 1:467. https://doi.org/10.1007/ s42452-019-0496-2

32. Sahu NK, Andhare AB (2019) Prediction of residual stress using RSM during turning of Ti-6Al-4V with the 3D FEM assist and experiments. SN Appl Sci,891.https://doi.org/10.1007/s4245 2-019-0809-5

33. Rajput V, Goud M, Suri NM (2020) Finite element modelling for analyzing material removal rate in ECDM. J Adv Manufact Syst. https://doi.org/10.1142/S0219686720500365

34. Bhondwe KL, Yadava V, Kathiresan G (2006) Finite element prediction of material removal rate due to electrochemical spark machining. Int J Mach Tool Manuf 46:1699-1706

35. Wei C, Xu K, Ni J et al (2011) A finite element based model for electrochemical discharge machining. Int J Adv Manuf Tech 54(9-12):987-995
36. Goud MM, Sharma AK (2017) A three-dimensional finite element simulation approach to analyze material removal in electrochemical discharge machining. Proc IMechE C J Mech Eng Sci 231(13):2417-2428. https://doi.org/10.1177/095440621663616 7

37. Panda MC, Yadava V (2009) Finite element prediction of material removal rate due to traveling wire electrochemical spark machining. Int J Adv Manuf Technol 45:506-520

38. Karazi SM, Ahad IU, Benyounis KY (2017) Laser micromachining for transparent materials. Reference Module in Materials Science and Materials Engineering 2017.

39. Jui SK, Kamaraj AB, Sundaram MM (2013) High aspect ratio micromachining of glass by electrochemical discharge machining (ECDM). J Manuf Process 15(4):460-466

40. Cao XD, Kim BH, Chu CN (2009) Micro structuring of glass with features less than $100 \mu \mathrm{m}$ by electrochemical discharge machining. Precis Eng 33:459-465. https://doi.org/10.1016/j.precisione ng.2009.01.001

Publisher's Note Springer Nature remains neutral with regard to jurisdictional claims in published maps and institutional affiliations. 